NBER WORKING PAPER SERIES

\begin{abstract}
SCALING UP MALARIA CONTROL IN AFRICA: AN ECONOMIC AND EPIDEMIOLOGICAL ASSESSMENT
\end{abstract}

\author{
Awash Teklehaimanot \\ Gordon C. McCord \\ Jeffrey D. Sachs \\ Working Paper 13664 \\ http://www.nber.org/papers/w13664
}
NATIONAL BUREAU OF ECONOMIC RESEARCH
1050 Massachusetts Avenue
Cambridge, MA 02138

December 2007

The authors would like to thank Drs. Simon Hay and Robert Snow for providing the Lysenko and malaria risk maps for our use. In addition, Dr. Yemane Ye-ebiyo Yihdego was enormously helpful in clearing up details in the costing. Dr. Maru Aregawi Weldedawit kindly provided some references in the epidemiology literature. Finally, thanks to Adam Storeygard and Yuri Gorokhovich for answering questions on GIS software. The views expressed herein are those of the author(s) and do not necessarily reflect the views of the National Bureau of Economic Research.

(C) 2007 by Awash Teklehaimanot, Gordon C. McCord, and Jeffrey D. Sachs. All rights reserved. Short sections of text, not to exceed two paragraphs, may be quoted without explicit permission provided that full credit, including $\odot$ notice, is given to the source. 
Scaling Up Malaria Control in Africa: An Economic and Epidemiological Assessment Awash Teklehaimanot, Gordon C. McCord, and Jeffrey D. Sachs

NBER Working Paper No. 13664

December 2007

JEL No. I18

\begin{abstract}
$\underline{\text { ABSTRACT }}$
This paper estimates the number of people at risk of contracting malaria in Africa using GIS methods and the disease's epidemiologic characteristics. It then estimates yearly costs of covering the population at risk with the package of interventions (differing by level of malaria endemicity and differing for rural and urban populations) for malaria as recommended by the UN Millennium Project. These projected costs are calculated assuming a ramp-up of coverage to full coverage by 2008, and then projected out through 2015 to give a year-by-year cost of meeting the Millennium Development Goal for reducing the burden of malaria by $75 \%$ We conclude that the cost of comprehensive malaria control for Africa is US\$3.0 billion per year on average, or around US\$4.02 per African at risk.
\end{abstract}

Awash Teklehaimanot

The Earth Institute at Columbia University 2910 Broadway

Hogan Hall Mail Code: 3277

New York, NY 10025

at2076@columbia.edu

Gordon C. McCord

The Earth Institute at Columbia University

314 Low Library

535 West 116th Street, MC 4327

New York, NY 10027

gm2101@columbia.edu
Jeffrey D. Sachs

The Earth Institute at Columbia University 314 Low Library

535 West 116th Street, MC 4327

New York, NY 10027

and NBER

sachs@columbia.edu 


\section{INTRODUCTION}

The burden of malaria in Africa continues to be extremely high, despite the existence of effective interventions to curb the mortality and morbidity of the disease. Every year, up to three million people die from malaria on the continent. ${ }^{1}$ The Millennium Development Goals set in 2000 recognize that malaria must be controlled if Africa is to escape from the cycle of extreme poverty and disease. The MDG on malaria is to "Have halted by 2015 and begun to reverse the incidence of malaria,” which has been made more specific by the UN Millennium Project's working group on malaria as “Reduce malaria morbidity and mortality by 75 percent by 2015 from the 2005 baseline level.” In January 2005, the working group on malaria recommended that countries where malaria is rife should use an integrated package of preventive and treatment

methods to achieve this goal. ${ }^{2}$ The project also recommended that insecticide treated mosquito bed nets and effective malaria drugs be given away free of charge, a move endorsed by UN Secretary-General Kofi Annan in March, and by heads of state at the UN World Summit in September 2005.

There are existing, effective methods to control malaria: prevent people from being bitten by mosquitoes — using insecticide treated bed nets and insecticide spray applications — treat those who get infected with effective drugs such as artemisinin-based combination therapies (ACTs), promote health education and communication, and conduct monitoring and evaluation. This paper estimates the number of people at risk of contracting malaria in Africa using GIS methods, and then estimates the yearly costs of covering the population at risk with the package of interventions recommended by the UN Millennium Project.

\section{DERIVATION OF POPULATION AT RISK}


Due to lack of adequate data collection in Africa's health system, there is incomplete information on the morbidity and mortality associated with malaria. ${ }^{3}$ The WHO Global Burden of Disease program estimates burden in Africa through “active” case-detection studies of populations living under different transmission intensity risks, which is subject to underdetection. Several alternative studies have estimated population at risk using other methods, including estimates based on national surveys, ${ }^{4}$ estimates based on climate suitability for malaria transmission, ${ }^{5,6}$ and estimates based on maps of the geographic extent of malaria in a Geographic Information System (GIS). ${ }^{7}$

We follow the GIS-based strategy by overlaying the following maps: a high-resolution (30 arc-seconds) map of 2005 human population; $^{8}$ a map of country boundaries, the most recent (2002) map of the extent malaria of risk ${ }^{9}$ (shown below); a map of malaria endemicity levels constructed in $1968^{10}$ (shown below); and a map of the extent of urban areas. ${ }^{8}$ The latter four maps were rasterized to the same 30 arc-second cell size. Population sums were then calculated by country for the following categories: total population within the malaria risk zone, population within a malaria risk zone and within an urban zone, population within a malaria risk zone and within a zone of unstable malaria transmission (either hypoendemic or mesoendemic zones in the endemicity map), and population within a malaria risk zone, an urban zone, and a zone of unstable transmission. (Note that areas showing up on the 1968 endemicity map but are outside the area of 2002 malaria risk are considered to no longer have malaria and are ignored). The resulting estimate for population at risk of malaria in Africa in 2006 is 672 million people, of which 485 million are in rural areas (see Table 1). Finally, we used the UN Population Division's median forecast of projected population to calculate a population growth rate for each country, and used it to estimate the population in each country in the above categories for every year 
between 2006 and 2015. This now allows us to calculate the cost of each intervention, by country and by year, based on the urban and rural population at risk, in stable and unstable malaria transmission areas.
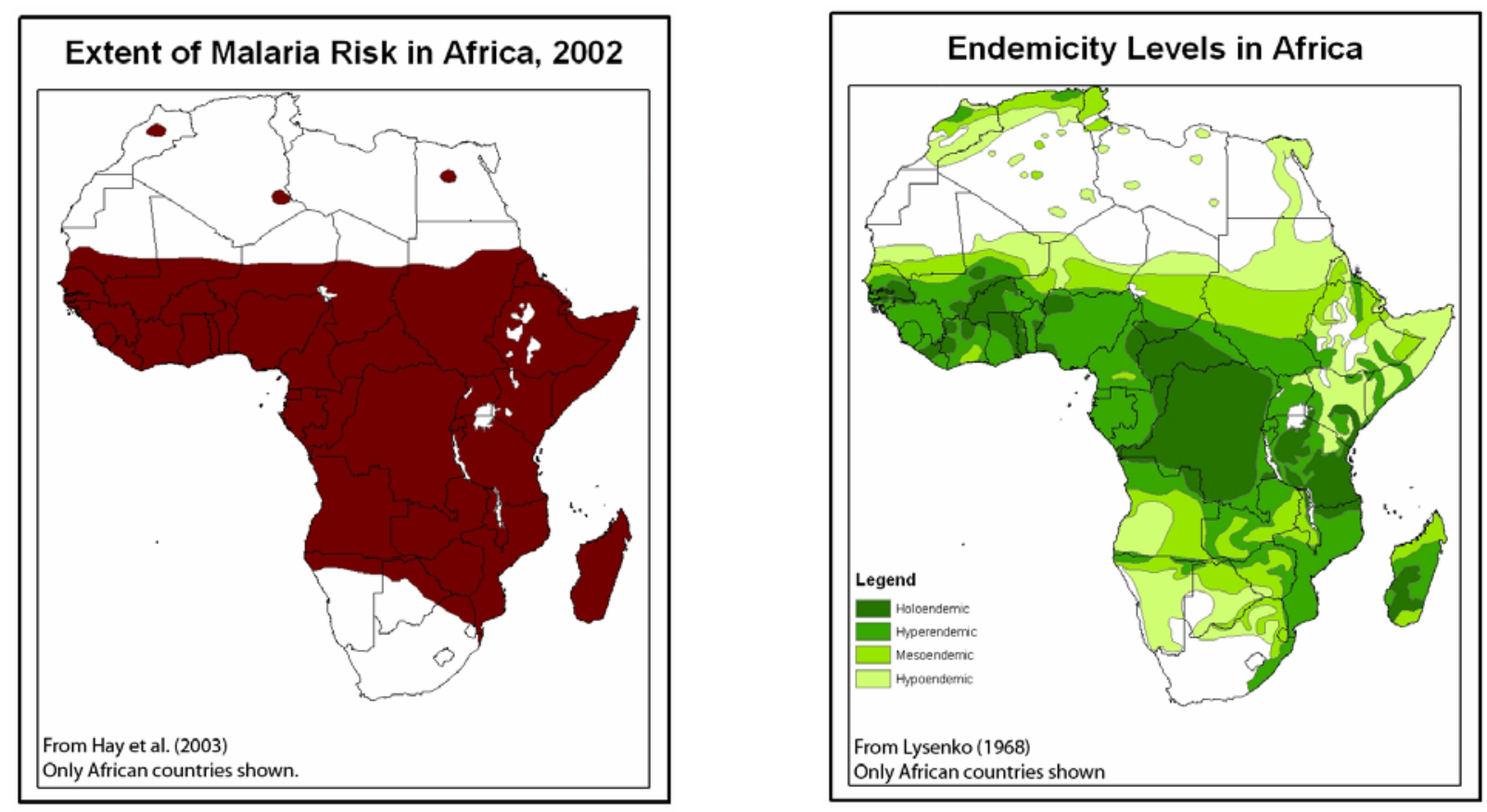

\section{DESCRIPTION OF COMPREHENSIVE INTERVENTIONS}

The interventions included in this costing exercise encompass most of the key interventions recommended by the UN Millennium Project, and many details of the costing follow those of the report of the Working Group on Malaria. ${ }^{2}$ For prevention of disease, they include long-lasting insecticidal bed nets (LLINs), indoor residual spraying (IRS) in unstable transmission areas, training of community health workers, and cost of an information, education, and communication program. For enhanced diagnosis and treatment, they include microscopy, rapid diagnostic tests, effective drugs such as artemisinin-combination therapies (ACTs) for uncomplicated malaria, and treatment of severe malaria. Finally, the costing includes resources 
for monitoring and evaluation, and for the overhead costs of a global push on malaria control. Below are the assumptions made for each intervention:

- Long-Lasting Insecticidal Nets (LLINs): Following the UN Millennium Project's recommendation, we calculate the cost of complete coverage of LLINs for the population at risk by the end of 2008, with a ramp-up of coverage during 2006, 2007, and 2008. Note that this is a more ambitious target than other costing exercises; the efficacy of LLINs and the mass action effect implies that the entire population, and not just children and pregnant women, should be targeted by LLIN distribution programs. ${ }^{11}$ We assume that one net is needed for every two people at risk. The cost of LLINs is around \$5, with an additional \$2 estimated cost of storage and distribution, and the net needs to be replaced after 5 years (as is the case with Olyset nets). ${ }^{12}$ Note that long-lasting nets do not need to be re-impregnated with insecticide during their 5-year lifespan.

- Indoor Residual Spraying (IRS): Selective vector control (including IRS) was part of the WHO’s Global Strategy for Malaria Control which was adopted by the Ministerial Conference in 1992 and subsequently endorsed by the World Health Assembly (WHA) and the UN General Assembly. The Global Strategy was also taken up by the RBM partnership for the use of selective control in appropriate epidemiological settings. Recently, the U.S.'s President's Malaria Initiative (PMI) has also emphasized the benefits of IRS. We have estimated the average annual cost of using IRS against malaria in unstable transmission areas at \$206 million. However, the cost of blanket spraying all malaria transmission areas is $\$ 1.1$ billion or up to $\$ 2$ billion considering intense 
transmission areas require more than one round of spraying per year. Thus blanket coverage with IRS seems prohibitively expensive, especially since intense transmission areas will be scaling up LLIN coverage, and LLINs are easier to distribute, last for up to five years, face less complex logistic challenges than IRS, and require fewer human resources. We therefore include costs for IRS in unstable transmission areas only, since these areas higher risks of mortality (note that there are some stable transmission areas of special economic consideration, such as resorts or mining operations, where private sector budgets will cover the high per capita costs of IRS). We assume that Lysenko's map of endemicity in Africa continues to represent relative transmission strength in Africa today, since unlike other parts of the world, the continent has benefited from few anti-malaria interventions. We consider the areas of the 2002 extent of malaria risk which are hypoendemic and mesoendemic in Lysenko's map to be low- and moderatetransmission and thus recommended for IRS. (This area, encompassing much of eastern African, part of southern Africa and the Sahel countries is roughly the area experts describe as having unstable transmission ${ }^{13}$ ). By overlaying this area with the population map, we estimate that 149 million people lived in low- and moderate-transmission areas in Africa in 2005. We follow the costing methodology of the UN Millennium Project Working Group on Malaria. Since costs are at the household level, we assume an average of 5 people per household, that each household has about $300 \mathrm{~m}^{2}$ of surface that needs to be sprayed, that each square meter requires 2.67 grams of insecticide (DDT, the insecticide of choice), add a ten percent margin of insecticide, and use a cost of US\$4.3 per kilogram of insecticide (this cost corresponds to DDT). In addition, we cost labor requirements for IRS. We divide number of households by 360 person-days to get the 
number of spray persons needed. We assume 5 spray persons for each squad, 5 squads for each team and for each technician, and 1 supervisor for 5 teams. Wages were set at US\$10 per day for the spray persons (for 40 days of work plus 6 training days), US\$15 per day for squad chiefs and technicians (both also for 46 days), and US\$20 per day for supervisors (for 18 person-days of work). For field equipment, we include a tent (US\$2000) for each team and each supervisor, and add \$100 per person for all personnel for coveralls, handgloves, goggles, buckets, soaps, etc., and US\$0.06 in forms and stationary for each household sprayed. For the first year (2006) we include the cost of the spray pump and spare parts (US\$500) for each spray person. Finally, we recognize the costs of other logistics, including vehicles to transport equipment and personnel, spare parts and maintenance, fuel and lubricant, and insurance for the spraying team and vehicles. Since the UN Millennium Project Working Group on Malaria estimated costs for these items in Ethiopia based on number of districts, we cannot replicate the costing in this exercise (since we are only working with population at risk in each country). We therefore totaled these costs (for every year) in the Working Group’s exercise and found them to be $30 \%$ of the other costs of IRS (which we do model). We therefore added $30 \%$ of total IRS costs as an estimate of the cost of logistics.

- Training Community Health Workers (CHW): An RBM survey indicated that between $70 \%$ and $90 \%$ of febrile children are treated at home. ${ }^{2}$ There is therefore an urgent need to treat uncomplicated malaria at the community level, especially given evidence of decreased child mortality among those who see a community health worker $(\mathrm{CHW}) .{ }^{14} \mathrm{~A}$ number of countries are seeking to improve coverage by extending health 
services using CHWs for malaria diagnosis and treatment services. We assume that one CHW is needed per 500 population, and that training for malaria control lasts 8 days and costs $\$ 10$ per day. .

- Human Resource Development: Note that there are other needs in human resource development; the Malaria Working Group indicates that besides CHWs, training of nurses, physicians, entomologists and malariologists will be needed to guide and implement the program activities. However, these costs are estimated based on the size of the formal health sector (number of hospitals, etc.), and are not estimated based on the size of the population at risk. We approximate the costs based on the methodology of the Working Group on Malaria as follows: we consider the total cost of leadership training for program managers and topping up salary for medical officers, epidemiologists, entomologists, biologists, health officers, nurses, environmental health workers, and malaria technicians. The estimated costs total \$704 million for Ethiopia from 2005--2015. Using our estimate of population at risk, we find that this number of human resource development needs translates into around \$1.00 per person at risk per year, and use the same assumption for all countries in Africa based on population at risk.

- Microscopy: We expect that health facilities such as health centers, rural hospitals, and all hospitals in urban areas will use microscopic examination of stained thick and thin blood smears, the gold standard for malaria diagnosis. The Working Group on Malaria estimates the cost of microscopy using the numbers of hospitals and other health centers in a country, which cannot be duplicated in this paper. We therefore estimate the cost of 
microscopy as we did for topping-up of salaries. The Working Group on Malaria estimated that the total cost of microscopy for Ethiopia from 2005--2015 to be around \$29 million. Using our estimates of population at risk, we find that this number is equivalent to around $\$ 0.04$ per person at risk per year, and use this number to estimate microscopy costs for all the countries. Note that microscopes can be used for other purposes (TB, other parasitic and bacterial diseases).

- Rapid Diagnostic Testing (RDT): Given that peripheral levels of the health system particularly rural areas - often cannot meet the laboratory requirements for microscopy, a variety of simple and rapid diagnostic tests have been developed for accurate and reliable malaria diagnosis by community health workers and health facilities. We assume that RDT should be used only in unstable transmission areas, for all age groups.

In areas of intense transmission, where severe disease and mortality are largely concentrated in children under five years of age, malaria should be treated on the basis of clinical suspicion of malaria and not on confirmed diagnosis by RDTs. People older than 5 years of age have a well developed level of immunity, are at lesser risk of developing severe malaria and a significant proportion are asymptomatic in the presence of malaria parasites. This group (above 5 years old living in intense transmission areas) constitutes the bulk of the febrile cases in Africa (we estimate around 218 million fever episodes) and at the moment will be too expensive to subject every one of them to RDT examination. They should therefore be treated clinically on the basis of seasonality and clinical manifestation of the disease. 
We use the UN Population Division’s World Population Prospects' demographic breakdown for every year between 2006 and 2015 to divide our population at risk into groups aged 0--4, 5--9, 10--14, and 14+. Following WHO guidelines, the first age group does not require RDT, since in patients below age 5 every fever episode immediately receives malaria treatment due to the possibility of misdiagnosis. ${ }^{15}$ Following similar assumptions to the costing done by the UN Millennium Project Working Group on Malaria, the 5--9 and 10--14 age groups are assumed to experience one fever episode per year and the age 14+ group experiences 0.5 fever episodes per year (these are taken as the average number of fevers from all causes, across all endemicity levels). One RDT kit is needed for each of these fever episodes (again, we restrict ourselves to unstable transmission areas), and costs at US\$0.61 per kit. Note, that we have built into the model a decrease in fever episodes as LLIN coverage increases: we assume that the proportion of the population covered by LLINs has a 50\% reduction in fever episodes (measured reduction in morbidity has ranged from $44 \%--75 \%{ }^{16,17,18,19}$ ). This decreases the need for RDT as LLIN coverage increases. Moreover, we have assumed that the number of fever episodes for populations living in urban areas is $25 \%$ smaller, since transmission tends to be lower in urban areas.

- Artemisinin-based Combination Therapies (ACTs): We again calculated fever episodes for each of the four age groups mentioned above (including the 0--4 age group, which we assume experience 2 fever episodes per year). We assume that RDT in unstable transmission areas will reveal that around $40 \%$ of the fevers are due to malaria and 
require ACTs (as was assumed by the UN Millennium Project Working Group on Malaria). In intense transmission areas, on the other hand, we assume that $20 \%$ of the fever episodes will be examined by microscopy, and these will have a slide positivity rate of $40 \%$ (Ethiopia’s current slide positivity rate). The $80 \%$ of fevers not examined by microscopy all require ACTs. Our total number of fever episodes requiring malaria treatment in 2006 is 395 million, which is within the range of other published estimates. ${ }^{20}$ We assume that each treatment course can be treated with either artemether-lumefantrine or artesunate-amodiaquine. Artemether-lumefantrine is assumed to cost US\$0.45 for the 0--4 age group, US $\$ 0.90$ for the 5--9 age group, US $\$ 1.35$ for the 10--14 age group, and US\$1.80 for the $14+$ age group. ${ }^{21,22}$ Artesunate-amodiaquine is estimated to cost US\$0.23 for the children under 1, $\$ 0.45$ for the 1--6 age group, US $\$ 0.80$ for the 7--13 age group, and $\$ 1.48$ for the 13+ age group (we use RBM's recommended dosages ${ }^{23}$ and averages of prices from Sanofi-Aventis, Ipca, and Cipla, ${ }^{24}$ and adjust to match age groups in our analysis). We use the average of the cost of artemether-lumefantrine and artesunateamodiaquine. As above, we assume a 50\% reduction in fever episodes for the population covered by LLINs, and 25\% fewer fever episodes among urban populations. For intense transmission areas, this is a 50\% reduction in all fevers; for unstable transmission areas, it is a $50 \%$ reduction of fevers that needs ACTs, that is, a $50 \%$ reduction of the original $40 \%$ of total fevers. ACT production is a bottleneck, as discussed below; we assume that enough ACTs will be produced to meet need starting in 2008, but for 2006 and 2007 there will be a shortage. We include a US $\$ 0.10$ cost of using other drugs (sulfadoxinepyrimethamine (SP)-amodiaquine combination or SP-chloroquine combination) to treat the fevers that will not be treated with ACTs in 2006 and 2007. It is expected that in a 
year's time, ACTs such as dihydroartemisinin piperaquine will become available, resulting in overall increased production and cost reduction.

- Management of Severe Malaria: We include a rough approximation of management of severe malaria, using the median cost of $\$ 29.50$ for managing a severe malaria case as derived by WHO/AFRO ${ }^{25}$ We assume that about $1 \%$ of the malaria episodes would progress to severe malaria. ${ }^{26}$

- Information, Education and Communication: A program to educate communities and promote behavioral change is an important element in successful malaria reduction. The program should produce information, education, and communication materials targeting health workers, community leaders, and communities; it should use radio spots, television, drama and other educational media to increase treatment-seeking behavior, compliance, and use of LLINs, target IRS; and organize sensitization and advocacy meetings at district, regional, and national levels. The Working Group on Malaria estimated that the cost of IEC for Ethiopia $\$ 614,000$ per year. Using our estimates of population at risk, we find that this number is equivalent to around $\$ 0.011$ per person at risk per year, and use this number to estimate IEC costs for all the countries.

- Monitoring and Evaluation: Monitoring and evaluation are essential components of malaria control programs to track effectiveness of the interventions over time. Activities involve assessment of routine health services data and periodic community and household surveys in order to develop process indicators for implementation, and 
outcome indicators for case management, prevention, and program impact. ${ }^{27}$ In addition, the effectiveness of antimalarials and insecticides must be monitored. Following the standard practice in programs funded by the Global Fund to fight AIDS, TB and Malaria, we add $7 \%$ of costs as monitoring and evaluation.

- Overhead Costs: Finally, we add $10 \%$ of the cost to account for the overhead costs in a global effort to reach full coverage of these malaria interventions by 2008 .

Using our estimated population at risk and the costing assumptions above, we arrive at the projected total yearly costs for all of Africa shown in Table 2 and graphed below:

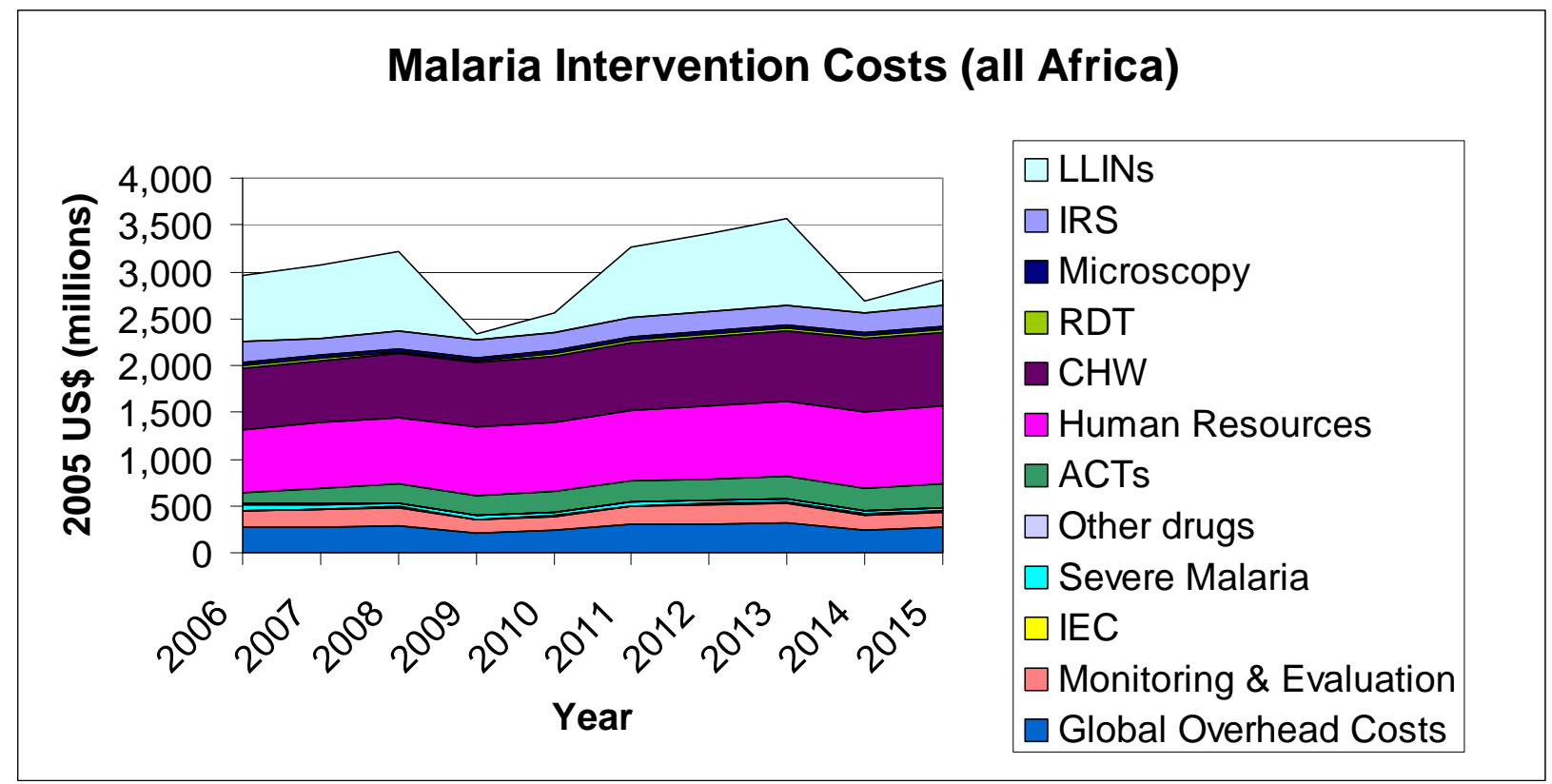

The most striking fact from these numbers is their modest magnitude. Given that we are talking about a disease that kills around two million African children every year, the fact that full 
coverage of LLINs and ACTs (plus the other interventions) costs only \$3.00 per African (or \$4.02 per person at risk of malaria) is astounding and encouraging.

We examined these numbers in comparison with earlier studies. The UN Millennium Project Working Group on Malaria performed a detailed costing of interventions for Ethiopia, and arrived at an average of US\$238 million per year, which comes to around US\$2.70 per capita per year (compared to \$3.00 in our results above; note that unlike the working group, we include salaries for CHWs, without which our per capita cost is \$2.29). Another costing estimate (Kiszewski A and others, unpublished) of malaria interventions for Africa results in $\$ 1.7$ billion, an equivalent of around US\$2.10 per person at risk per year. It is heartening that our GIS-based approach and different costing assumptions produce similar results and corroborate the magnitude of the per capita cost of these interventions.

\section{SCALING UP TO FULL COVERAGE IN 2008}

Given that our model assumes full coverage of LLINs by the end of 2008, it is instructive to look at costs before 2008 carefully. In order to reach full coverage of all interventions by 2008, the international community needs to begin planning ahead to guarantee sufficient production of LLINs and ACT treatment courses. Full coverage in 2008 means that around 352 million nets must be distributed in Africa by the end of that year. Around 20 million nets have been distributed in 2005 (the Global Fund to fight AIDS, TB and Malaria - the largest provider of resources for malaria control in Africa - has approved purchases of around 22--31 million LLINs between 2005 and 2007, and we looked at the GFATM disbursement reports and found that roughly 20 million nets had been distributed in 2005). Our costing model above includes a ramping up of distribution to 100 million new nets in 2006, 110 million new nets in 2007, and 
122 million new nets in 2008. Since production of LLINs by the two producing companies (Sumitomo and Vestergaard) in 2006 is currently planned for around 80 million nets, the donor countries should commit as soon as possible to funding a scale up of production in 2007 and 2008 so that full coverage can be reached by 2008. Two other LLIN products from other manufacturers are also expected to be in the market soon, which would alleviate the production capacity constraint.

With regard to treatment, the current estimate for production of ACTs in 2006 is 130 million treatment doses, which is insufficient to meet the estimated 395 million treatments needed. In 2006 and 2007, our costing model assumes that fevers that cannot be treated with ACTs will be treated with either SP-amodiaquine combination or SP-chloroquine combination, which both cost about US\$0.10. By 2008, we assume that enough ACTs will be produced to meet the need, which our projections show to be around 251 million treatment courses. This implies a doubling of ACT production between now and 2008. For our model, we use the estimated 130 million treatment courses for 2006 production, and in order to ramp up to 251 million by 2008, we use 200 million as the number of ACT treatments produced in 2007. Again, since ACTs are produced by private companies, this increase in production can only happen if donors agree in advance to purchase the required treatment courses.

Note that this costing exercise was carried out in early 2006; since scale up in 2006 has been slower than expected, this implies a faster scale up will be needed in 2007 and 2008, and full coverage could perhaps be reached by early 2009. The important point, however, is that full coverage can be reached within approximately three years, and average annual costs between now and 2015 are not high. 


\section{CONCLUSION}

We have employed a GIS-based method to estimate the population in Africa at risk of contracting malaria, and proceeded to calculate the cost of providing this population a comprehensive set of interventions to reduce malaria incidence and mortality. The interventions in our model are adjusted for urban areas and for unstable transmission areas. Although these estimates are rough and cannot replace country-specific malaria planning and cost estimates, the exercise shows that a GIS-based costing strategy comes up with comparable results to methods that estimate population at risk using survey methods. In areas where survey methods may severely underestimate population at risk, GIS-based estimates provide a useful alternative method. Ideally, maps of malaria risk and intensity will be updated frequently in the future to provide up-to-date estimates given the impact of interventions. Our results make it evident that the costs of comprehensive malaria interventions are very low on a per-capita or per-patient basis. Nevertheless, full coverage is beyond the reach of African government budgets. Given that the disease kills millions, is readily preventable and curable, and has been shown to hamper economic development, the international community should seize the opportunity to reduce massively this human disease burden at such a low cost. Other public health efforts, such as measles and polio campaigns currently underway, present an opportunity to synergize by also delivering malaria interventions, especially bed nets. ${ }^{28,29}$

\section{ACKNOWLEDGEMENTS}

The authors would like to thank Drs. Simon Hay and Robert Snow for providing the Lysenko and malaria risk maps for our use. In addition, Dr. Yemane Ye-ebiyo Yihdego was enormously helpful in clearing up details in the costing. Dr. Maru Aregawi Weldedawit kindly 
provided some references in the epidemiology literature. Finally, thanks to Adam Storeygard and Yuri Gorokhovich for answering questions on GIS software. 


\begin{tabular}{|c|c|c|c|c|c|c|c|c|c|c|c|}
\hline \multirow[b]{4}{*}{ Algeria } & \multirow[b]{4}{*}{$\frac{\text { Total }}{0.00}$} & \multirow[b]{4}{*}{$\frac{\text { Urban }}{0.00}$} & \multirow[b]{4}{*}{$\frac{\text { Rural }}{0.00}$} & \multicolumn{8}{|c|}{ By Endemicity Level } \\
\hline & & & & \multirow{2}{*}{\multicolumn{4}{|c|}{$\frac{\text { Intensive (Holoendemic + Hyperendemic) }}{\text { By Age Group }}$}} & \multirow{2}{*}{\multicolumn{4}{|c|}{\begin{tabular}{|c|} 
Unstable (Mesoendemic + Hypoendemic) \\
By Age Group \\
\end{tabular}}} \\
\hline & & & & & & & & & & & \\
\hline & & & & $\frac{0-4}{0.00}$ & $\frac{5-9}{0.00}$ & $\frac{10-14}{0.00}$ & $\frac{14+}{0.00}$ & $\frac{0-4}{0.00}$ & $\frac{5-9}{0.00}$ & $\frac{10-14}{0.00}$ & $\frac{14+}{0.00}$ \\
\hline Angola & 15.60 & 4.87 & 10.73 & 1.23 & 0.97 & 0.86 & 3.54 & 1.68 & 1.32 & 1.17 & 4.83 \\
\hline Benin & 7.58 & 2.92 & 4.66 & 1.29 & 1.09 & 0.95 & 4.25 & 0.00 & 0.00 & 0.00 & 0.00 \\
\hline Botswana & 0.70 & 0.25 & 0.45 & 0.00 & 0.00 & 0.00 & 0.02 & 0.08 & 0.08 & 0.09 & 0.42 \\
\hline Burkina Faso & 13.88 & 1.75 & 12.13 & 2.57 & 2.12 & 1.84 & 7.36 & 0.00 & 0.00 & 0.00 & 0.00 \\
\hline Burundi & 6.55 & 0.45 & 6.09 & 1.16 & 0.92 & 0.84 & 3.63 & 0.00 & 0.00 & 0.00 & 0.00 \\
\hline Cameroon & 16.54 & 7.09 & 9.45 & 2.42 & 2.18 & 2.06 & 9.64 & 0.04 & 0.03 & 0.03 & 0.14 \\
\hline Central African Republic & 4.00 & 1.51 & 2.49 & 0.62 & 0.56 & 0.51 & 2.26 & 0.01 & 0.01 & 0.01 & 0.03 \\
\hline Chad & 9.14 & 1.85 & 7.30 & 1.25 & 0.99 & 0.84 & 3.42 & 0.51 & 0.40 & 0.34 & 1.40 \\
\hline Comoros & 0.62 & 0.15 & 0.47 & 0.10 & 0.09 & 0.07 & 0.36 & 0.00 & 0.00 & 0.00 & 0.00 \\
\hline Congo & 3.70 & 2.36 & 1.33 & 0.69 & 0.57 & 0.48 & 1.95 & 0.00 & 0.00 & 0.00 & 0.00 \\
\hline Congo, Dem. Rep. & 60.13 & 17.66 & 42.48 & 11.76 & 9.11 & 7.60 & 31.66 & 0.00 & 0.00 & 0.00 & 0.00 \\
\hline Côte d'Ivoire & 17.17 & 6.91 & 10.26 & 2.01 & 1.81 & 1.70 & 7.77 & 0.59 & 0.53 & 0.50 & 2.27 \\
\hline Djibouti & 0.59 & 0.40 & 0.19 & 0.00 & 0.00 & 0.00 & 0.00 & 0.09 & 0.08 & 0.07 & 0.35 \\
\hline Egypt & 0.00 & 0.00 & 0.00 & 0.00 & 0.00 & 0.00 & 0.00 & 0.00 & 0.00 & 0.00 & 0.00 \\
\hline Equatorial Guinea & 0.50 & 0.19 & 0.31 & 0.09 & 0.07 & 0.06 & 0.28 & 0.00 & 0.00 & 0.00 & 0.00 \\
\hline Eritrea & 4.70 & 0.60 & 4.10 & 0.06 & 0.05 & 0.05 & 0.20 & 0.74 & 0.64 & 0.55 & 2.40 \\
\hline Ethiopia & 57.86 & 7.57 & 50.29 & 3.98 & 3.45 & 3.09 & 13.26 & 5.70 & 4.94 & 4.43 & 19.01 \\
\hline Gabon & 1.32 & 0.94 & 0.37 & 0.18 & 0.17 & 0.17 & 0.80 & 0.00 & 0.00 & 0.00 & 0.00 \\
\hline Gambia, The & 1.44 & 0.76 & 0.69 & 0.22 & 0.19 & 0.17 & 0.87 & 0.00 & 0.00 & 0.00 & 0.00 \\
\hline Ghana & 21.80 & 7.64 & 14.16 & 3.02 & 2.76 & 2.63 & 13.39 & 0.00 & 0.00 & 0.00 & 0.00 \\
\hline Guinea & 9.18 & 2.83 & 6.36 & 1.54 & 1.30 & 1.16 & 5.18 & 0.00 & 0.00 & 0.00 & 0.00 \\
\hline Guinea-Bissau & 1.37 & 0.40 & 0.97 & 0.27 & 0.21 & 0.17 & 0.72 & 0.00 & 0.00 & 0.00 & 0.00 \\
\hline Kenya & 33.03 & 6.78 & 26.25 & 4.31 & 3.52 & 3.08 & 14.60 & 1.27 & 1.04 & 0.91 & 4.30 \\
\hline Liberia & 3.15 & 1.15 & 1.99 & 0.61 & 0.48 & 0.40 & 1.66 & 0.00 & 0.00 & 0.00 & 0.00 \\
\hline Libya & 0.00 & 0.00 & 0.00 & 0.00 & 0.00 & 0.00 & 0.00 & 0.00 & 0.00 & 0.00 & 0.00 \\
\hline Madagascar & 18.70 & 3.57 & 15.13 & 2.38 & 2.13 & 1.82 & 8.12 & 0.70 & 0.63 & 0.54 & 2.39 \\
\hline Malawi & 12.72 & 2.15 & 10.57 & 0.53 & 0.47 & 0.40 & 1.56 & 1.75 & 1.56 & 1.31 & 5.14 \\
\hline Mali & 13.40 & 3.15 & 10.25 & 2.38 & 1.96 & 1.65 & 6.45 & 0.18 & 0.15 & 0.13 & 0.50 \\
\hline Mauritania & 1.30 & 0.34 & 0.96 & 0.00 & 0.00 & 0.00 & 0.01 & 0.22 & 0.18 & 0.15 & 0.73 \\
\hline Morocco & 2.53 & 0.91 & 1.62 & 0.05 & 0.04 & 0.04 & 0.31 & 0.22 & 0.21 & 0.21 & 1.45 \\
\hline Mozambique & 20.25 & 5.82 & 14.43 & 3.20 & 2.80 & 2.51 & 10.90 & 0.14 & 0.12 & 0.11 & 0.47 \\
\hline Namibia & 1.10 & 0.24 & 0.87 & 0.09 & 0.09 & 0.09 & 0.39 & 0.06 & 0.06 & 0.06 & 0.26 \\
\hline Niger & 13.01 & 2.17 & 10.85 & 1.27 & 1.00 & 0.80 & 3.18 & 1.37 & 1.08 & 0.86 & 3.45 \\
\hline Nigeria & 128.29 & 44.66 & 83.63 & 21.51 & 18.42 & 16.48 & 71.76 & 0.02 & 0.02 & 0.02 & 0.07 \\
\hline Rwanda & 8.77 & 0.59 & 8.17 & 1.46 & 1.22 & 1.10 & 4.99 & 0.00 & 0.00 & 0.00 & 0.00 \\
\hline Sao Tome and Principe & 0.15 & 0.06 & 0.09 & 0.02 & 0.02 & 0.02 & 0.09 & 0.00 & 0.00 & 0.00 & 0.00 \\
\hline Senegal & 10.64 & 4.59 & 6.06 & 0.82 & 0.72 & 0.66 & 3.01 & 0.85 & 0.75 & 0.69 & 3.14 \\
\hline Sierra Leone & 5.41 & 1.69 & 3.71 & 0.94 & 0.74 & 0.64 & 3.09 & 0.00 & 0.00 & 0.00 & 0.00 \\
\hline Somalia & 10.38 & 2.36 & 8.02 & 0.86 & 0.71 & 0.56 & 2.68 & 1.00 & 0.82 & 0.65 & 3.11 \\
\hline South Africa & 6.15 & 1.49 & 4.67 & 0.02 & 0.02 & 0.02 & 0.13 & 0.65 & 0.64 & 0.64 & 4.03 \\
\hline Sudan & 33.48 & 10.21 & 23.27 & 0.68 & 0.62 & 0.56 & 2.91 & 4.08 & 3.73 & 3.38 & 17.53 \\
\hline Swaziland & 0.00 & 0.00 & 0.00 & 0.00 & 0.00 & 0.00 & 0.00 & 0.00 & 0.00 & 0.00 & 0.00 \\
\hline Tanzania, United Republic & 37.17 & 11.68 & 25.49 & 5.33 & 4.79 & 4.35 & 19.77 & 0.46 & 0.41 & 0.37 & 1.69 \\
\hline Togo & 5.28 & 1.69 & 3.60 & 0.86 & 0.75 & 0.67 & 3.00 & 0.00 & 0.00 & 0.00 & 0.00 \\
\hline Uganda & 27.83 & 3.51 & 24.32 & 5.65 & 4.44 & 3.63 & 13.45 & 0.14 & 0.11 & 0.09 & 0.33 \\
\hline Zambia & 11.59 & 4.12 & 7.47 & 1.09 & 0.95 & 0.86 & 3.45 & 0.90 & 0.78 & 0.71 & 2.85 \\
\hline Zimbabwe & 13.05 & 4.84 & 8.21 & 0.61 & 0.59 & 0.60 & 2.77 & 1.13 & 1.09 & 1.12 & 5.13 \\
\hline All Africa & "671.78 & 186.85 & 484.94 & 89.13 & 75.11 & 66.17 & 288.82 & 24.58 & 21.44 & 19.12 & 87.42 \\
\hline
\end{tabular}

Table 2: Cost Estimates:

\begin{tabular}{|c|c|c|c|c|c|c|c|c|c|c|c|}
\hline Totals (millions of US\$) & 2006 & 2007 & 2008 & 2009 & 2010 & 2011 & 2012 & 2013 & 2014 & 2015 & Average \\
\hline LLINS & 700 & 770 & 854 & 58 & 199 & 760 & 831 & 916 & 121 & 263 & 547 \\
\hline IRS & 223 & 187 & 191 & 195 & 200 & 204 & 209 & 213 & 218 & 222 & 206 \\
\hline $\mathrm{CHW}$ & 645 & 660 & 676 & 692 & 708 & 724 & 741 & 758 & 776 & 793 & 717 \\
\hline Microscopy & 28 & 28 & 29 & 30 & 30 & 31 & 32 & 33 & 33 & 34 & 31 \\
\hline Human Resources & 677 & 693 & 709 & 726 & 743 & 760 & 778 & 796 & 814 & 832 & 753 \\
\hline RDT & 40 & 33 & 25 & 26 & 26 & 27 & 27 & 28 & 29 & 29 & 29 \\
\hline ACTs & 109 & 168 & 212 & 217 & 222 & 227 & 232 & 238 & 243 & 249 & 212 \\
\hline Other drugs & 26 & 13 & 0 & 0 & 0 & 0 & 0 & 0 & 0 & 0 & 4 \\
\hline Severe Malaria & 54 & 45 & 34 & 35 & 36 & 36 & 37 & 38 & 39 & 40 & 39 \\
\hline IEC & 7 & 7 & 7 & 8 & 8 & 8 & 8 & 8 & 9 & 9 & 8 \\
\hline Monitoring \& Evaluation & 176 & 182 & 192 & 139 & 152 & 194 & 203 & 212 & 160 & 173 & 178 \\
\hline Global Overhead Costs & 268 & 279 & 293 & 212 & 232 & 297 & 310 & 324 & 244 & 264 & 272 \\
\hline Total & 2,953 & 3,065 & 3,222 & 2,337 & 2,556 & 3,270 & 3,408 & 3,564 & 2,684 & 2,908 & 2,997 \\
\hline Total per total population (dollars) & $\$ 3.24$ & $\$ 3.29$ & $\$ 3.39$ & $\$ 2.41$ & $\$ 2.58$ & $\$ 3.23$ & $\$ 3.30$ & $\$ 3.38$ & $\$ 2.49$ & $\$ 2.65$ & $\$ 3.00$ \\
\hline Total per person at risk (dollars) & $\$ 4.40$ & $\$ 4.46$ & $\$ 4.58$ & $\$ 3.24$ & $\$ 3.47$ & $\$ 4.33$ & $\$ 4.41$ & $\$ 4.51$ & $\$ 3.32$ & $\$ 3.52$ & $\$ 4.02$ \\
\hline
\end{tabular}




\title{
AUTHORS’ ADDRESSES
}

\author{
Awash Teklehaimanot \\ 2910 Broadway MC 3277 \\ Hogan Hall, 110B \\ New York, NY 10025 \\ awash@ei.columbia.edu \\ Gordon C. McCord \\ 314 Low Library, MC 4327 \\ 535 West $116^{\text {th }}$ Street \\ New York, NY 10027 \\ gm2101@columbia.edu \\ fax: (212) 854-8702 \\ Jeffrey D. Sachs \\ 314 Low Library, MC 4327 \\ 535 West $116^{\text {th }}$ Street \\ New York, NY 10027 \\ sachs@columbia.edu \\ fax: (212) 854-8702
}

\footnotetext{
${ }^{1}$ Breman JG, Alilio MS, Mills A, 2004. Conquering the intolerable burden of malaria: what's new, what's needed: a summary. Am J Trop Med Hyg 71: suppl:1--15.

${ }^{2}$ UN Millennium Project, 2005. Coming to Grips with Malaria in the New Millennium. Task Force on HIV/AIDS, Malaria, TB and Access to Essential Medicines, Working Group on Malaria. Sterling, VA: Earthscan.

${ }^{3}$ WHO, 1996. World Malaria Situation in 1993. Weekly Epidemiological Record. 19 January. No. 1, pp. 17--22.

${ }^{4}$ Snow RW, Eckert E, Teklehaimanot A, 2003. Estimating the needs for artesunate-based combination therapy for malaria case-management in Africa. Trends Parasitol, Vol. 19, No. 8 August, 363--369.

${ }^{5}$ Craig MH, Snow RW, le Sueur D, 1999. A climate-based distribution model of malaria transmission in subSaharan Africa. Parasitol Today 15, 105--111.

${ }^{6}$ Snow RW, Craig M, Deichmann U, Marsh K, 1999. Estimating mortality, morbidity and disability due to malaria among Africa’s non-pregnant population. Bull World Health Organ. 77, 624--640.

${ }^{7}$ Snow RW, Guerra CA, Noor AM, Myint HY, Hay SI, 2005. The global distribution of clinical episodes of Plasmodium falciparum malaria. Nature. Mar 10; 434(7030):214--217.
} 
${ }^{8}$ Center for International Earth Science Information Network (CIESIN), Columbia University; International Food Policy Research Institute (IPFRI); the World Bank; and Centro Internacional de Agricultura Tropical (CIAT); 2004. Global Rural-Urban Mapping Project (GRUMP): Urban/Rural Extents. Palisades, NY: CIESIN, Columbia University. Available at http://sedac.ciesin.columbia.edu/gpw. Downloaded March 2006.

${ }^{9}$ Hay SI, Guerra CA, Tatem AJ, Noor AM, Snow RW, 2004. The global distribution and population at risk of malaria: past, present and future. Lancet Infect Dis. Vol. 4 (June), 327--336.

${ }^{10}$ Lysenko AJ, Semashko IN, 1968. Geography of malaria. A medico-geographic profile of an ancient disease. In: Lebedew AW, ed. Itogi Nauki: Medicinskaja Geografija. Moscow, USSR: Academy of Sciences, 25--146.

${ }^{11}$ Curtis C, Maxwell C, Lemnge M, Kilama WL, Steketee RW, Hawley WA, Bergevin Y, Campbell C, Sachs J, Teklehaimanot A, Ochola S, Guyatt H, Snow RW, 2003. Scaling-up coverage with insecticide-treated nets against malaria in Africa: who should pay? Lancet Infect Dis. Vol 3, May, 304--307.

${ }^{12}$ WHO/RBM/UNICEF/PSI/MSH, 2004. Sources and Prices of Selected Products for the Prevention, Diagnosis and Treatment of Malaria. France, WHO.

${ }^{13}$ Kiszewski AE, Teklehaimanot A, 2004. A Review of the Clinincal and Epidemiologic Burdens of Epidemic Malaria. Am J Trop Med Hyg 71(Suppl 2), 128--135.

${ }^{14}$ Alemayehu T, Ghebreyesus TA, Witten KH, Bosman A, Teklehaimanot A, 1998. Community-based malaria control programme in Tigray Region, Northern Ethiopia: Results of a mortality survey of rural under-five children. Ethiopian Journal of Health Development. 12(3): 203--211.

${ }^{15}$ WHO, 2005. The role of laboratory diagnosis to support malaria disease management: Focus on the use of RDTs in areas of high transmission. Report of informal consultation (25--26 October 2004). Geneva: WHO (prepublication copy). Available at http://www.who.int/malaria/docs/ReportLABdiagnosis-web.pdf. Accessed December 30, 2006.

${ }^{16}$ Lengeler C, 2004. Insecticide-treated bed nets and curtains for preventing malaria. Cochrane Database Syst Rev. ${ }^{17}$ WHO/UNICEF, 2003. Africa Malaria Report 2003. Available at http://www.who.int/malaria/amd2003/amr2003/pdf/amr2003.pdf. Accessed December 30, 2006. 
${ }^{18}$ Maxwell CA, Msuya E, Sudi M, Njunwa KJ, Carneiro IA, Curtis CF, 2002. Effect of community-wide use of insecticide-treated nets for 3--4 years on malarial morbidity in Tanzania. Trop Med Int Health 7(12), Dec: 1003-1008.

${ }^{19}$ Nevill CG, Some ES, Mung’ala VO, Mutemi W, New L, Marsh K, Lengeler C, Snow RW, 1996. Insecticidetreated bednets reduce mortality and severe morbidity from malaria among children on the Kenyan coast. Trop Med Int Health Apr; 1(2): 139--146.

20 The World Malaria Report 2005 (RBM/WHO/UNICEF) estimates between 210--300 million clinical cases in Africa. Snow RW et al. (2003) estimate 1.7 billion fever episodes in Africa per year, and find cost of treating $60 \%$ of these fevers with ACTs. Snow RW et al. (2005), meanwhile, estimate 365 million clinical cases in 2002.

${ }^{21}$ Novartis, 2006. “Media Release (September 29, 2006): Novartis announces initiative to improve access to stateof-the-art anti-malarial treatment Coartem.” Available at www.novartis.com. Accessed January 31, 2007.

${ }^{22}$ Correspondence with WHO.

${ }^{23}$ WHO, 2006. Guidelines for the Treatment of Malaria. Switzerland: WHO.

${ }^{24}$ RBM, 2006. ACTs Procured by WHO and UNICEF. Available at: http://www.rbm.who.int/docs/mmss/actSourcesPrices_catalogue.pdf. Accessed December 30, 2006.

${ }^{25}$ WHO/AFRO, 2002. Clinical, Behavioural and Socioeconomic Factors Related to Severe Malaria: a Multicentre Study in the African Region. Available at http://www.who.int/malaria/cmc upload/0/000/016/330/multicenter.pdf. Accessed December 30, 2006.

${ }^{26}$ Greenwood B, Marsh K, Snow R, 1992. Why do some African children develop severe malaria? Parasitol Today. Nov; 8(11): 381-383.

${ }^{27}$ Bryce J, Roungou JB, Nguyen-Dinh P, Naimoli JF, Breman JH. Evaluation of national malaria control programmes in Africa. 1994. Bull World Health Organ (72: 371--381).

${ }^{28}$ Grabowsky M, Nobiya T, Ahun M, Donna R, Lengor M, Zimmerman D, Ladd H, Hoekstra E, Bello A, BaffoeWilmot A, Amofah G, 2003. Linking ITN distribution to measles campaigns achieves high and rapid coverage at low cost. Proceedings of the annual meeting of the American Society of Tropical Medicine and Hygiene. Philadelphia, 4 Dec, Abstract 1230. 
${ }^{29}$ American Red Cross and CORE, 2004. "Malaria Case Study Partnerships in Action: An Integrated Approach to Combining a Measles Campaign with a Bed Net, Vitamin A and Mebendazole Campaign in Zambia,” July. (available online at http://pdf.dec.org/pdf_docs/PNADB968.pdf). 